\title{
An event-related brain potential study of inhibition of return
}

\author{
JOHN J. MCDONALD, LAWRENCE M. WARD, and KENT A. KIEHL \\ University of British Columbia, Vancouver, British Columbia, Canada
}

\begin{abstract}
Event-related brain potentials (ERPs) were recorded during two spatial-cuing experiments using nonpredictive cues. Our primary goal was to determine the electrophysiological consequences of inhibition of return (IOR). At long (>500 msec) cue-target intervals, subjects responded more slowly to targets that appeared at or near the cued location, relative to targets that appeared on the opposite side of fixation from the cue. This behavioral IOR effect was associated with cue-validity effects on several components of the target-elicited ERP waveforms. The earliest such effect was a smaller occipital P1 on valid-cue trials, which we interpret as a $\mathrm{P} 1$ reduction. The $\mathrm{P} 2$ component was also smaller on validcue trials, indicating that nonpredictive spatial cues influence multiple stages of information processing at long cue-target intervals. Both of these effects were observed when sensory interactions between cue and target were likely to be negligible, indicating that they were not caused by sensory refractoriness. A different effect of cue validity, the posterior negative difference, was found when sensory interactions were likely to be greatest, indicating that it could arise from sensory refractoriness.
\end{abstract}

It is well established that focusing attention in a particular region of the visual field facilitates the detection and identification of visual stimuli occurring at that location (for reviews, see Van der Heijden, 1992; Wright \& Ward, 1998). One of the most common techniques for assessing the behavioral effects of selective attention is the spatial-cuing paradigm, in which the location of a forthcoming target stimulus is cued in advance. Studies of this kind show that humans are able to use a symbolic cue, such as a centrally presented arrow, to voluntarily shift attention in the visual field. As a result of this attention shift, subjects are typically faster and more accurate to respond to targets occurring at the validly cued (expected) location, relative to targets occurring at invalidly cued (unexpected) locations. This effect occurs in the absence of eye movements, indicating that covert attention mechanisms are involved. Facilitatory effects also occur in response to direct spatial cues, such as luminance increments, suggesting that salient visual events may also generate attention shifts (see, e.g., Jonides, 1981). These latter cue effects are

The results of Experiment 1 were presented at the meeting of the Cognitive Neuroscience Society, San Francisco, 1996. This work was supported by a grant and graduate scholarship from the Natural Sciences and Engineering Research Council of Canada (NSERC). We thank Robert Hare and Peter Liddle for use of their ERP equipment. Correspondence concerning this article should be addressed to J. J. McDonald, Department of Neurosciences, University of California, San Diego, 9500 Gilman Drive, Mailcode 0608, La Jolla, CA 92093-0608 (e-mail: jmcd@sdepl.ucsd.edu), or to L. M. Ward, Department of Psychology, University of British Columbia, 2136 West Mall, Vancouver, BC V6T 1Z4, Canada (e-mail: lward@cortex. psych.ubc.ca).

-Accepted by previous editor, Myron L. Braunstein said to be stimulus driven, because they occur even when the peripheral signal does not accurately predict the target's position.

It is also well established that behavioral costs can accompany attention-related behavioral benefits (for a review, see Rafal \& Henik, 1994). One type of cost is an apparent inhibition of perceptual processing that occurs when a target appears at an invalidly cued location (i.e., the cost of an invalid cue). In trial-by-trial cuing paradigms, this inhibition has roughly the same time course as the facilitation (or benefit) that appears at the cued location. By comparison, a second type of cost is observed at the cued location after the facilitatory effect has diminished. At longer cue-target stimulus onset asynchronies (SOAs), subjects are actually slower to respond to targets presented at the cued location than to targets presented at uncued locations (see, e.g., Maylor, 1985; Maylor \& Hockey, 1985; Posner \& Cohen, 1984). This effect is referred to as inhibition of return (IOR; Posner, Rafal, Choate, \& Vaughan, 1985) or as the inhibitory aftereffect (Tassinari, Aglioti, Chelazzi, Marzi, \& Berlucchi, 1987). The IOR effect lasts at least 1,000$1,500 \mathrm{msec}$ (Posner \& Cohen, 1984), long enough to influence several saccadic eye movements. Consequently, IOR may bias strategic visual scanning by decreasing the likelihood of returning to previously stimulated locations.

Since its initial discovery, the IOR phenomenon has been the focus of much debate. One issue concerns the possible ways in which IOR is established. One popular hypothesis is that IOR is produced from orienting attention to, or away from, the cued location (e.g., Maylor, 1985; Maylor \& Hockey, 1985). However, covert orienting is not sufficient to generate IOR, since the effect does not normally arise from symbolic cuing. A second hypothesis is that IOR depends on sensory stimulation (Posner \& 
Cohen, 1984). A third hypothesis is that IOR is related to activation of the oculomotor system (e.g., Rafal, Calabresi, Brennan, \& Sciolto, 1989; Tassinari et al., 1987). A fourth hypothesis is that IOR is associated with a tagging procedure for keeping track of visual objects (e.g., Tipper, Driver, \& Weaver, 1991; Wright \& Richard, 1996).

A second major issue concerns the processes that are influenced by IOR. This issue pertains to the consequence, rather than to the mechanism, of IOR (see LaBerge, 1995, for a discussion of the mechanisms and consequences of spatial attention). The IOR effect might reflect an attenuation in sensory-perceptual processing of targets appearing at the cued location, or it might simply be a delay in initiating a motor response (either oculomotor or manual). The first proposal is generally consistent with the characterization of IOR as an attentional effect (i.e., that it influences attentional processes), since attention is known to influence sensory-perceptual processing under many circumstances. The second proposal is generally inconsistent with the characterization of IOR as an attentional phenomenon.

One popular interpretation of the IOR effect claims that attention is inhibited from moving to previously cued locations, thereby influencing perceptual processing at those locations. However, several findings indicate that IOR may be more closely associated with responding than with perceptual processing. For example, nonpredictive spatial cues often have no influence on temporalorder judgments at long SOAs (Maylor, 1985; Posner et al., 1985). By comparison, there is evidence for a strong temporal-order bias in favor of the cued location at short SOAs when the cue is spatially nonpredictive (Maylor, 1985 ) and at long SOAs when the cue is spatially predictive (Stelmach \& Herdman, 1991). Under these latter conditions, subjects report seeing a stimulus at the cued location before seeing a stimulus in the opposite hemifield, even when the two stimuli appear simultaneously. These results are taken as evidence that attention facilitates visual encoding, so that a stimulus at the cued location has prior entry to the perceptual system (Sternberg \& Knoll, 1973). That IOR fails to have the opposite effect on temporal-order judgments suggests that it does not influence sensory-perceptual processes (Klein \& Taylor, 1994; Maylor, 1985).

In contrast with the above evidence, several recent observations indicate that IOR does influence perceptual processes under some conditions. First, IOR occurs in tasks requiring speeded temporal-order judgments, although it may be reduced by the appearance of multiple targets (Gibson \& Egeth, 1994; but see Klein, Schmidt, \& Müller, 1998). Second, IOR can occur in tasks that require choice responses based on discrimination of perceptual features (Cheal, Chastain, \& Lyon, 1998; Pratt, 1995; Pratt, Kingstone, \& Khoe, 1997; but see Klein \& Taylor, 1994; Terry, Valdes, \& Neill, 1994). Third, several important parallels between IOR and attentional costs and benefits have been discovered, suggesting that IOR, like attention, may influence perceptual processes by inhibiting attention from returning to previously cued locations (ReuterLorenz, Jha, \& Rosenquist, 1996).

The two issues outlined in the preceding paragraphs are important because IOR might provide a reliable measure of the inhibitory processes that are involved in selective attention. However, as the preceding review demonstrates, neither the mechanisms of IOR nor their consequences are adequately understood. In the experiments reported here, we examined the electrophysiological consequences of IOR by recording event-related brain potentials (ERPs) from human subjects while they participated in spatialcuing tasks. Before turning to our specific predictions, the ERP methodology and its application to the study of covert spatial orienting will be briefly reviewed.

\section{Effects of Spatial Cues on \\ Human Brain Electrophysiology}

The electrical activity of the human brain can be measured by placing electrodes on a person's scalp and amplifying the electrical signals that penetrate the skull and scalp tissue. The voltage variation that is recorded by the scalp electrodes is called the electroencephalogram (EEG), and the fluctuations that are related to the processing of a specific stimulus event are called ERPs. ERPs typically reflect postsynaptic potentials generated by large groups of neurons that are activated simultaneously by a particular stimulus or event. The small ERP signal can be extracted from the ongoing EEG by averaging the ERPs over many trials, so that randomly occurring fluctuations in the EEG cancel each other out. The resulting ERP waveform consists of several positive $(\mathrm{P})$ and negative $(\mathrm{N})$ peaks that are related to various aspects of sensory, cognitive, and motor processing.

Researchers have examined the electrophysiological expression of voluntary (endogenous) spatial attention by recording ERPs during transient and sustained attention tasks. The general finding is that attention-related behavioral effects are accompanied by amplitude enhancements of the early Pl (90-140 msec) and NI (150-200 msec) components for attended stimuli, as compared with unattended stimuli (e.g., Eason, 1981; Harter, Aine, \& Schroeder, 1982; Hillyard \& Mangun, 1987; Mangun \& Hillyard, 1988; Rugg, Milner, Lines, \& Phalp, 1987). The scalp distribution of the P 1 effect, which is largest over lateral-occipital recording sites, is consistent with a neural generator located in the extrastriate visual cortex (Clark \& Hillyard, 1996; Heinze et al., 1994; Mangun, Hillyard, \& Luck, 1993). Consequently, the P1 attention effect has been interpreted as reflecting variations in ventral stream visual processing (see Ungerleider \& Mishkin, 1982). Enhancement of the $\mathrm{N} 1$ amplitude appears to reflect changes in occipital-parietal (dorsal) areas of the visual cortex (Mangun et al., 1993). Similar ERP enhancements occur regardless of whether attention is voluntarily sustained over a block of trials or is shifted on a trial-by-trial basis in response to a symbolic cue (for a review, see Mangun, 1995). 


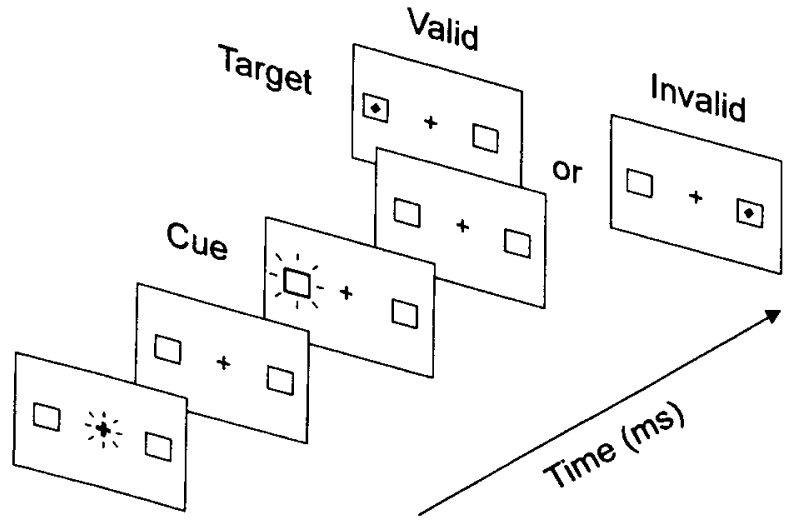

Figure 1. An example of the stimulus display sequences used in Experiments 1 and 2. In Experiment 1, the cue was a brief brightening of an unfilled box centered around one of the two peripheral target locations (as shown). In Experiment 2, the cue was a brief brightening of a bar located $4^{\circ}$ below one of the two peripheral target locations (as described in the text). The variable cue-target onset asynchrony is obtained by adding the cue duration ( $67 \mathrm{msec})$ to the variable interval that follows.

Researchers have also started to investigate the electrophysiological expression of stimulus-driven attention by examining the effects of direct spatial cues on targetelicited ERP waveforms (Anllo-Vento, 1995; Eimer, 1994; Hillyard, Luck, \& Mangun, 1994; Hopfinger \& Mangun, 1998). For example, Hopfinger and Mangun found that the lateral-occipital P1 was larger on valid-cue trials than on invalid-cue trials at short cue target SOAs, even though the cue did not predict the target's location. This Pl effect was accompanied by faster choice response times (RTs) on valid-cue trials than on invalid-cue trials. Together, these findings indicate that nonpredictive spatial cues summon attention automatically and that this stimulus-driven attention shift enhances perceptual processes at the cued location when the cue-target SOA is sufficiently short.

\section{Goals of the Present Study}

We examined the electrophysiological consequences of nonpredictive spatial cuing. Our primary goal was to identify the specific ERP changes that accompany the IOR effect at longer ( $>500 \mathrm{msec}$ ) cue-target intervals. We predicted that if IOR reflects changes in perceptual processing, the sensory-related components of the targetelicited ERPs would be smaller on valid-cue than on invalid-cue trials. On the other hand, if IOR acts exclusively to inhibit responding, the effects of cue validity will be confined to later components that are associated with preparing and generating the response. We tested these predictions by running two experiments in which we recorded ERPs while subjects made simple detection responses to visual targets following valid or invalid visual cues. Experiment 1 is similar to previous behavioral studies of IOR, in that a nonpredictive cue was presented either to the left or to the right of fixation and was fol- lowed, after a variable delay, by a peripheral target. In Experiment 2, we examined the extent to which a nonpredictive spatial cue would influence the target-elicited ERP waveform when sensory interactions between the cue and the target were reduced.

\section{EXPERIMENT 1}

\section{Method}

Subjects. Ten pard volunteers participated in the experıment. The data from 3 subjects were discarded because of excessive EEG artifacts caused by eye movements, eye blınks, and muscle activity. The remaining subjects consisted of 2 females and 5 males. All of these subjects (ages, 20-27 years; mean age, 22.1 years) were righthanded and had normal or corrected-to-normal vision.

Stimuli and Apparatus. Stimulus presentation and response recording were controlled by a 486-based IBM-compatible microcomputer. The stımuli were displayed on a 15-in. VGA monitor with a black background. The subjects sat in a dimly lit room and v1ewed the display from a distance of $50 \mathrm{~cm}$ with their heads restIng on an adjustable chinrest. The screen contınuously displayed a white fixation cross in the center and two square boxes in the extreme left and right peripheries. The fixation cross measured $0.5^{\circ}$ $\times 0.5^{\circ}$. The peripheral boxes measured $2.6^{\circ} \times 2.6^{\circ}$, with centers located $12^{\circ}$ of visual angle from the central fixatıon cross. The cue stımuli were $75-\mathrm{msec}$ brightenıngs of the perıpheral boxes. The target stimuli were $1.0^{\circ}$ white diamonds that filled the center of the peripheral boxes and remained present until the subjects responded by pressing a response key with their right index fingers. Responses were tımed to an accuracy of $1 \mathrm{msec}$, using a custom hardware timer.

Procedure. The subjects were instructed to maintain eye fixation on the central cross throughout the experiment and to respond as quickly as possible to the target diamond. After a $1,000-\mathrm{msec}$ intertrial interval (ITI), each trial began with a 100 -msec flicker of the fixation cross, followed $700 \mathrm{msec}$ later by the onset of a cue. The cue appeared with equal probability from either the left or the right peripheral box. Following a variable SOA, a target then appeared with equal probability in either of the two peripheral boxes and remained visible untıl the subjects pressed the response key. The SOA was randomly selected on each trial from one of two intervals (500-700 msec and 900-1,100 msec), each with a rectangular distribution (to minımize the overlap between cue and target ERP). On catch trials, no target appeared, and the trial was terminated after a $1,500-\mathrm{msec}$ interval. An example of the display sequences used in Experiment 1 is shown in Figure 1.

The subjects ran in a single recording session consisting of 25 blocks of trials. Each block was made up of 20 data trials and lasted approximately $1.5 \mathrm{~min}$. Four of 20 trials in each block (20\%) were catch trials on which no target was presented. These were included in order to minimize response anticipation errors. Among the remaining 16 trials in each block, those in which the target was preceded by same-location or opposite-location cues were referred to as valid-cue and invalid-cue trials, respectively.

Electrophysiological recording. Scalp potentials were recorded with tin electrodes (ElectroCap International) from the following scalp sites: FP1, FP2, C3, C4, P3, P4, T3, T4, T5, T6, and OZ (of the International 10-20 System), OL and OR (located halfway between $\mathrm{O} 1$ and $\mathrm{T} 5$ and between $\mathrm{O} 2$ and T6, respectively), and POZ (located halfway between PZ and OZ). All these electrodes were referenced to the right mastoid and subsequently digitally rereferenced to an average of left and right mastoids. Eye position was monitored by the horizontal electrooculogram (EOG), using a pair of electrodes placed $1 \mathrm{~cm}$ lateral to the left and right outer canthi. Electrode impedance was kept below $5 \mathrm{k} \Omega$. The amplifier bandpass was $0.3-35 \mathrm{~Hz}$. EEG and EOG were continuously sampled at a rate of $256 \mathrm{~Hz}$. 
Table 1

Mean Response Times (RTs) and Mean Cue Effects (in Milliseconds)

for Targets as a Function of Visual Field, Cue Validity, and Stimulus

Onset Asynchrony (SOA, in Milliseconds) in Experiments 1 and 2

\begin{tabular}{|c|c|c|c|c|c|c|c|}
\hline \multirow[b]{3}{*}{ Experiment } & \multirow[b]{3}{*}{ SOA } & \multicolumn{6}{|c|}{ Visual Field } \\
\hline & & \multicolumn{3}{|c|}{ Left } & \multicolumn{3}{|c|}{ Right } \\
\hline & & Valid & Invalid & Cue Effect ${ }^{\dagger}$ & Valid & Invalid & Cue Effect ${ }^{\dagger}$ \\
\hline \multirow[t]{2}{*}{1} & $500-700$ & 322 & 306 & $-16^{*}$ & 316 & 305 & $-11^{*}$ \\
\hline & $900-1,100$ & 326 & 304 & $-22 *$ & 313 & 300 & $-13^{*}$ \\
\hline \multirow[t]{2}{*}{2} & $100-300$ & 348 & 355 & +7 & 347 & 351 & +4 \\
\hline & $500-700$ & 343 & 328 & $-15^{*}$ & 340 & 329 & $-11^{*}$ \\
\hline
\end{tabular}

${ }^{*} p<.025$, by Bonferroni two-tailed $t$ test, as described in text. †Invalid-cue RT minus valid-cue RT.

Data analysis. EEG and EOG were averaged off line, starting $200 \mathrm{msec}$ before the onset of the target and continuing for $1,200 \mathrm{msec}$. Epochs contaminated with eye movements, blinks, muscle artifacts, or amplifier blocking were manually removed prior to averaging. EOG was also averaged over the cue-target interval, to examine whether the subjects made eye movements to the cued location. Subjects were disqualified if their average EOG deviation over the cue-target interval exceeded $\pm 2 \mu \mathrm{V}$. EEGs from all the remaining subjects were averaged separately for all combinations of conditions (visual field: left vs. right; cue validity: valid vs. invalid; SOA: $500-700 \mathrm{msec}$ vs. $900-1,100 \mathrm{msec}$ ), resulting in eight ERPs for each subject at each electrode site. All the measures were taken relative to the mean voltage of the 100 -msec interval preceding the onset of the target.

The effects of the experimental variables on the behavioral and ERP data were assessed by repeated measures analyses of variance (ANOVAs). For the ERP data, separate analyses were performed for each lateral electrode pair in central (C3/C4), parietal (P3/P4), and occipital (OL/OR) scalp regions, because visible differences in the ERP morphology were observed between the three regions (see, also, Mangun \& Hillyard, 1991). In addition, separate analyses were performed for each cue-target SOA, because qualitatively different ERP effects were observed at those intervals. For the $900-1,100 \mathrm{msec}$ SOA, the ERP effects were examined within latency windows corresponding to P1 (120-160 msec), N1 (160-210 msec), P2 (210-280 msec for contralateral sites, $230-290 \mathrm{msec}$ for ipsilateral sites), and P3 (300-420 msec). Peak amplitude values were determined within the $\mathrm{Pl}$ and $\mathrm{N} 1$ latency windows, whereas mean amplitude values were calculated for the broader $\mathrm{P} 2$ and $\mathrm{P} 3$ windows. Similarly, for the 500-700 msec SOA, the ERP effects were examined within latency windows corresponding to P2 (190-270 msec for contralateral sites, $210-290 \mathrm{msec}$ for ipsilateral sites) and P3 $(300-420 \mathrm{msec})$. However, rather than examining the effects on P1 and $\mathrm{N} 1$ separately, we examined the ERP effects within a broader latency window that spanned the $\mathrm{P} 1$ and N1 peaks $(120-200 \mathrm{msec})$. This latency window was chosen on the basis of difference waves that we computed by subtracting the ERPs elicited by invalidly cued targets from ones elicited by validly cued targets. These difference waves revealed a bimodal negativity. The first peak occurred between 120 and $200 \mathrm{msec}$, and the second one occurred between 200 and $300 \mathrm{msec}$. Both peaks were largest at lateral-occipital electrode sites, indicating that they are unrelated to the negative differences (Nd-early and Nd-late) associated with attentional enhancement. The first peak appeared to correspond to changes in the P1-N1 complex, whereas the second one appeared to correspond to changes in the P2. We refer to the first negative difference as the posterior $\mathrm{Nd}$, in order to distinguish it from potentially separate $\mathrm{P} 1$ and $\mathrm{N} 1$ effects. The mean amplitude of the posterior Nd was calculated within the 120-200 msec latency window.
The amplitude measures for each SOA were analyzed by separate ANOVAs, with visual field (left vs. right), validity (valid vs. invalid), and recording hemisphere (left vs. right) as repeated measures factors. The RT data for each SOA were analyzed by a single ANOVA, with visual field (left vs. right), validity (valid vs. invalid), and SOA (500-700 vs. $900-1,100 \mathrm{msec})$ as repeated measures factors.

\section{Results}

Behavioral performance. RTs less than $100 \mathrm{msec}$ and greater than $1,000 \mathrm{msec}$ were treated as errors and were excluded from analysis. In addition, RTs falling three standard deviations or more from the mean were eliminated as errors. This procedure resulted in the removal of less than $3 \%$ of the data trials. Median RTs were calculated from the remaining data for each subject in each of the eight visual field $\times$ validity $\times$ SOA conditions. The means of these median RTs and the corresponding cue effects (invalid-cue RT minus valid-cue RT) are shown in Table 1. Responses occurred on less than $2 \%$ of the notarget catch trials.

Analysis of the RTs revealed a significant main effect for validity $[F(1,6)=54.6, p<.0005]$, with subjects slower to respond on valid-cue trials than on invalid-cue trials. Planned comparisons showed that the cue effect was significant at each of the four visual field $\times$ SOA conditions. ${ }^{1}$ These findings replicate previously reported observations (e.g., Maylor, 1985; Posner \& Cohen, 1984) and indicate that IOR was present behaviorally at both SOAs. There were no significant effects of visual field $[F(1,6)=1.0, p=.35]$ or $\mathrm{SOA}[F(1,6)=0.6, p=.5]$, nor were there any significant interactions among the factors. However, the visual field $\times$ SOA interaction approached significance $[F(1,6)=5.0, p=.07]$, suggesting that IOR may have been larger for left-side targets in our task, at least in the longer SOA condition (see Table 2).

Event-related potentials. Figures 2 and 3 display the grand-averaged ERP waveforms elicited by the target when the SOA varied randomly between $500-700 \mathrm{msec}$ and $900-1,100 \mathrm{msec}$, respectively. At both SOA intervals, the prominent deflections in the ERP waveforms at posterior recording sites were the $\mathrm{P} 1(120-160 \mathrm{msec})$, N1 $(160-200 \mathrm{msec})$, and P3 (300-500 msec). The N1 and 
Table 2

Mean Amplitudes (in Microvolts) of Event-Related Potentials (ERPs) to Targets in Valid-Cue and Invalid-Cue in Experiments 1 and 2

\begin{tabular}{|c|c|c|c|c|c|c|c|}
\hline \multirow[b]{2}{*}{ Experiment } & \multirow[b]{2}{*}{ SOA* } & \multirow[b]{2}{*}{ ERP } & \multirow[b]{2}{*}{ Site } & \multicolumn{2}{|c|}{ Amplitude } & \multicolumn{2}{|c|}{ Validity Effects $^{+}$} \\
\hline & & & & Valid & Invalid & $\mathrm{V}$ & $\mathrm{V} \times \mathrm{F} \times \mathrm{H}$ \\
\hline \multirow[t]{7}{*}{1} & $500-700$ & $\mathrm{Nd}$ & $\mathrm{OL} / \mathrm{OR}$ & 0.83 & 2.35 & 0.03 & n.s. \\
\hline & & $\mathrm{P} 2$ & $\mathrm{P} 3 / \mathrm{P} 4$ & 3.93 & 4.82 & 0.04 & n.s. \\
\hline & & $\mathrm{P} 3 \ddagger$ & $\mathrm{P} 3 / \mathrm{P} 4$ & 7.23 & 5.48 & 0.03 & 0.04 \\
\hline & $900-1,100$ & Pl & $\mathrm{OL} / \mathrm{OR}$ & 3.48 & 4.26 & $\mathrm{n} . \mathrm{s}$ & 0.03 \\
\hline & & $\mathrm{NI}$ & $\mathrm{P} 3 / \mathrm{P} 4$ & -2.06 & -1.29 & n.s. & n.s. \\
\hline & & P2 & P3/P4 & 3.99 & 4.91 & n.s. & n.s. \\
\hline & & P3 & $\mathrm{P} 3 / \mathrm{P} 4$ & 6.22 & 5.07 & 0.03 & 0.04 \\
\hline \multirow[t]{6}{*}{2} & $100-300$ & $\mathrm{Nd}$ & $\mathrm{OL} / \mathrm{OR}$ & 2.17 & 2.62 & n.s. & 0.01 \\
\hline & & P3 & P3/P4 & 5.96 & 5.56 & n.s. & n.s. \\
\hline & $500-700$ & $\mathrm{Pl}$ & $\mathrm{OL} / \mathrm{OR}$ & 2.33 & 3.00 & 0.05 & n.s. \\
\hline & & NI & P3/P4 & -1.87 & -1.24 & n.s. & n.s. \\
\hline & & $\mathrm{P} 2$ & $\mathrm{P} 3 / \mathrm{P} 4$ & 3.12 & 4.71 & 0.008 & n.s. \\
\hline & & P3 & P3/P4 & 5.73 & 5.34 & n.s. & n.s. \\
\hline
\end{tabular}

${ }^{*}$ Stimulus onset asynchronies (SOAs) are in milliseconds. 'Probability values for the effects of cue validity on the ERP amplitudes: V, cue validity; $F$, visual field; $H$, recording hemisphere. IIn both experiments, the cue-validity effects on the P3 were obtained from a single analysis of variance, with SOA as a within-subjects factor.

P3 component were both largest over parietal scalp locations and showed contralateral distributions. The Pl component, on the other hand, was largest at occipital sites and was symmetrically distributed. A symmetrically distributed P2 (190-280 msec) can also be seen in some of the posterior waveforms.

For the 500-700 msec SOA, the earliest effect of cue validity on the ERP waveforms was a modulation of the posterior $\mathrm{Nd}$ in the $120-200 \mathrm{msec}$ latency window. This effect was significant at occipital $[F(1,6)=7.3, p=.03]$ and parietal $[F(1,6)=13.1, p=.01]$ electrode sites. Inspection of the grand-averaged waveforms in Figure 2 reveals that the ERPs were more negative on valid-cue trials than on invalid-cue trials during this latency window at both contralateral and ipsilateral sites. As can be seen in Figure 2, this difference began at the onset of the $\mathrm{P} 1$ and continued for nearly $100 \mathrm{msec}$, until after the NI peak. A similar effect of cue validity was observed in the P2 latency window at the 500-700 msec SOA. Specifically, the P2 was smaller on valid-cue trials than on invalid-cue trials. This effect was significant at occipital $[F(1,6)=6.9, p=.04]$ and parietal $[F(1,6)=7.6, p=.03]$ electrode sites.

For the 900-1,100 msec SOA, the earliest effect of cue validity was a modulation of the $P 1$. This effect was significant at ipsilateral occipital sites [cue validity $\times$ visual field $\times$ recording hemisphere: $F(1,6)=7.7, p=.03$ ] and also approached significance at parietal sites [cue validity: $F(1,6)=4.1, p=.09$; cue validity $\times$ visual field $\times$ recording hemisphere: $F(1,6)=4.2, p=.08$ ]. Inspection of Figure 3 reveals that the P1 was smaller on valid-cue trials than on invalid-cue trials at ipsilateral sites. In contrast, cue validity did not influence the $\mathrm{N} 1$ or the $\mathrm{P} 2$ component at the $900-1,100 \mathrm{msec} \mathrm{SOA}$, although a $\mathrm{P} 2$ reduction on valid-cue trials can be observed in the grandaveraged waveforms (Figure 3).

For both SOAs, the P3 component was larger on validcue trials than on invalid-cue trials within the 300
420 msec latency window. To gain more statistical power, we analyzed the P3 data in a single ANOVA, with SOA as an additional within-subjects factor. The effect of cue validity was significant at parietal $[F(1,6)=7.5, p=.03]$ and occipital $[F(1,6)=10.4, p=.02]$ electrode sites. Inspection of Figures 2 and 3 shows that the P3 was larger on valid-cue trials than on invalid-cue trials at both contralateral and ipsilateral parietal sites, although this effect was larger at contralateral sites than at ipsilateral sites $[\mathrm{P} 3 / \mathrm{P} 4: F(1,6)=6.9, p=.04 ; \mathrm{OL} / \mathrm{OR}: F(1,6)=5.5$, $p=.05]$.

Electrooculograms. In order to be certain that the behavioral and ERP results obtained in Experiment 1 were not caused by changes in eye position, we examined the grand-averaged EOG recordings during the cue-target interval, to determine whether there were any consistent trends for subjects to look in the direction of the cue. The EOG recordings did not exceed $\pm 2 \mu \mathrm{V}$, indicating that the deviation of the eyes was quite small. On the basis of EOG recordings from additional subjects, who made eye movements to lights located $1.15^{\circ}$ left and right of the central fixation light-emitting diode (LED), we estimate that the subject's eye position was within $0.15^{\circ}$ of the central LED during the entire cue-target interval in Experiment 1.

\section{Discussion}

The behavioral results of Experiment 1 replicated the previously reported observation that nonpredictive spatial cues have an inhibitory effect on simple RT at relatively long SOAs (e.g., Maylor, 1985; Posner \& Cohen, 1984). Specifically, subjects were slower to respond to visual targets on valid-cue trials than on invalid-cue trials. This IOR effect was accompanied by several changes in the target ERP waveforms. At the longest SOA, the earliest effect was observed approximately $140 \mathrm{msec}$ after target onset and was manifested as a reduction of the occipital PI on valid-cue trials, relative to that on invalid- 
IPSILATERAL
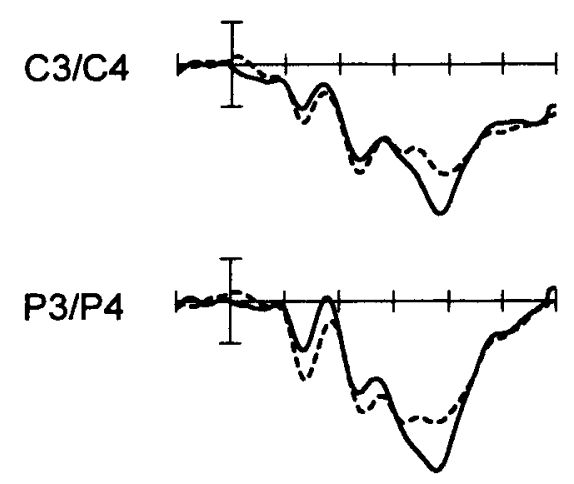

OL/OR

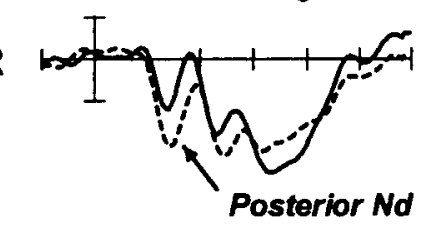

CONTRALATERAL
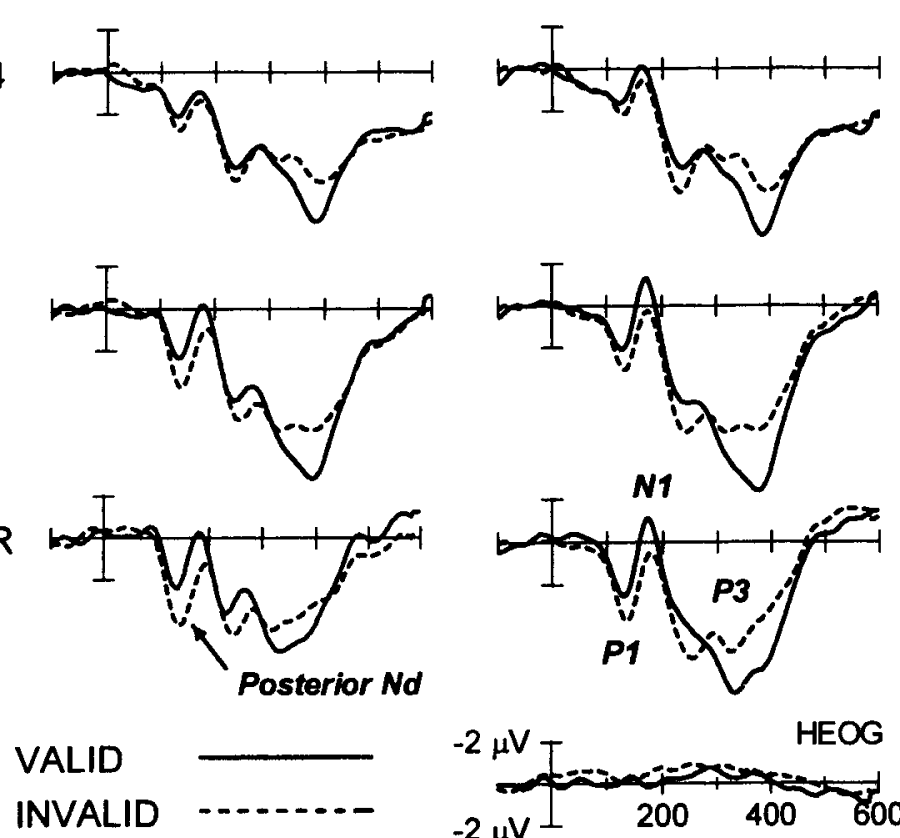

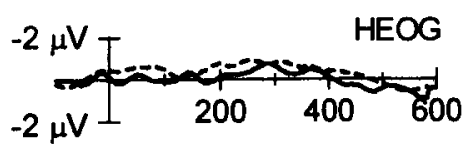

\begin{abstract}
Figure 2. Grand-averaged event-related potentials in response to targets preceded 500-700 msec by a valid (solid line) or invalid (dashed line) cue in Experiment 1. Waveforms shown are averaged across left-field and right-field target stimuli. Recordings shown are from left and right central ( $\mathrm{C} 3$ and $\mathrm{C} 4)$, parietal (P3 and P4), and lateral occipital (OL and OR) scalp sites. HEOG refers to the bipolar recordings of horizontal eye position.
\end{abstract}

cue trials. Since it is likely that the $\mathrm{Pl}$ component reflects activity in extrastriate visual areas (Clark \& Hillyard, 1996; Heinze et al., 1994; Mangun et al., 1993), our data indicate that nonpredictive spatial cues influenced sensory-perceptual processing at relatively long SOAs. This finding is consistent with the proposal that the behavioral IOR effect results, at least in part, from changes in perceptual processing. The $P 1$ reduction on valid-cue trials may reflect either suppressed processing of targets at the cued location or, alternatively, facilitated processing of targets at the uncued location (or both). It is difficult to determine which interpretation is better, because of the inherent difficulty in choosing a neutral baseline condition in direct-cuing paradigms (cf. Jonides \& Mack, 1984; Wright, Richard, \& McDonald, 1995).

The nonpredictive cue also affected longer latency ERP components, suggesting that IOR may influence multiple stages of processing. Like the Pl component, the occipitalparietal $\mathrm{P} 2$ was reduced on valid-cue trials, as compared with invalid-cue trials, at the 500-700 $\mathrm{msec}$ SOA. A similar $\mathrm{P} 2$ reduction can be observed at the $900-1,100 \mathrm{msec}$ SOA, but this effect did not reach significance. In addition, the amplitude of the P3 component was larger on valid-cue trials than on invalid-cue trials. Previous ERP studies indicate that the $\mathrm{P} 3$ reflects higher order pro- cessing associated with stimulus categorization. The P3 is particularly sensitive to target expectancies, insofar as its amplitude is usually larger for infrequent stimuli than for frequent stimuli (see, e.g., Donchin, 1981). On this basis, one interpretation of the present $\mathrm{P} 3$ findings is that validly cued targets were unexpected, although they occurred with the same frequency as invalidly cued targets. This interpretation, although speculative, is consistent with the proposal that IOR reflects changes in decisional and/or response processes.

The $\mathrm{Pl}$ reduction observed in this experiment could reflect sensory refractoriness, rather than suppression of perceptual processes. Sensory refractoriness refers to the reduction in an ERP component that occurs when the component's generator is in a refractory state. In the present case, this could have occurred because the generator of the $\mathrm{P} 1$ component was less responsive to the target on valid-cue trials following its response to the same-location cue. Such reductions of the $P 1$ peak would reflect a passive process, rather than an active one. Eimer (1994) argued that a similar P1 reduction in his study reflected sensory refractoriness, primarily because he observed no behavioral IOR.

Sensory refractoriness is an unlikely explanation for the $\mathrm{P} 1$ reduction at the $900-1,100 \mathrm{msec}$ SOA in the pres- 
IPSILATERAL
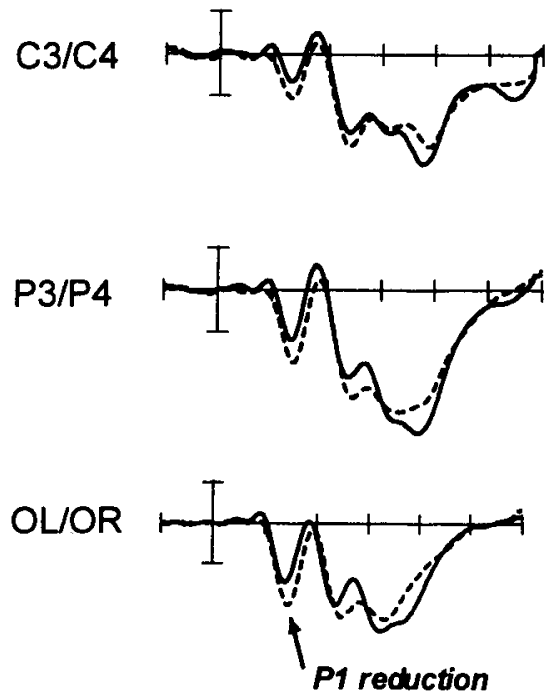

CONTRALATERAL
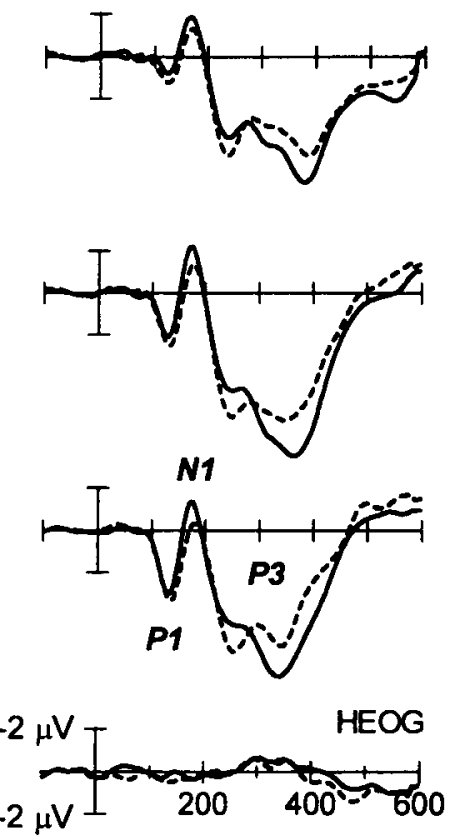

Figure 3. Grand-averaged event-related potentials in response to targets preceded 900-1,100 msec by a valid (solid line) or invalid (dashed line) cue in Experiment 1 . Waveforms are averaged across left-field and right-field target stimuli. Electrode positions are labeled as in Figure 2.

ent experiment, because passive sensory interactions do not usually occur when the interstimulus interval is greater than a few hundred milliseconds. Thus, although sensory refractoriness could have occurred at the shorter $500-700 \mathrm{msec}$ SOA, it was probably absent entirely at the longer one. Notably, qualitatively different ERP effects were observed at the two SOAs. At the $500-700 \mathrm{msec}$ SOA, the difference in average amplitude between the P1 and the $\mathrm{Nl}$ peaks (i.e., the Pl-Nl amplitude) was about the same on valid-cue trials as it was on invalid-cue trials, indicating that there was a single sustained effect of cue validity on the early ERP components. In contrast, there was a clear reduction only of $P 1$ amplitude on valid-cue trials at the longer SOA. To be consistent with standard terminology, we characterized the sustained effect at the shorter SOA as a posterior $\mathrm{Nd}$, because the ERP was more negative on valid-cue trials than on invalid-cue trials in the $120-200 \mathrm{msec}$ latency window. However, we could as easily have called it a reduced positivity. We suggest that the sustained effect observed at the 500-700 msec SOA could possibly have been the consequence of sensory refractoriness caused by response to the cue, whereas the $\mathrm{Pl}$ reduction observed at the $900-1,100 \mathrm{msec}$ SOA was a consequence of IOR. Although previous studies have reported $\mathrm{P} 1$ reductions following direct cues (e.g., Eimer, 1994), to our knowledge, this is the first time such an effect has been found in the absence of a sustained poste- rior $\mathrm{Nd}$ and, at the same time, associated with a corresponding behavioral effect.

It might be possible to weaken a sensory refractoriness explanation for the ERP data of Experiment 1 by investigating ERPs under conditions in which sensory interactions between the cue and the target have been reduced. Unlike most sensory effects, IOR can affect processing of stimuli in regions surrounding the cued location (Maylor \& Hockey, 1985; Tassinari et al., 1987) and can persist even when the cue and the target are seen in separate eyes (Maylor, 1983; Tassinari \& Berlucchi, 1993). In Experiment 2 , we examined the effects of nonpredictive spatial cues on ERP components under conditions in which sensory interactions between the cue and the target were reduced.

\section{EXPERIMENT 2}

Several methodological changes were made in order to reduce the sensory interactions between the cue and the target. First, the cue and target stimuli were presented to different eyes. These dichoptic viewing procedures, described below, eliminated all cue-target interactions occurring at the level of the retina, the lateral geniculate nucleus, and the input layer (4B) of the primary visual cortex, because cells in these areas respond to input from only one eye. However, many cells in higher visual areas 
respond to input from either eye, and thus, they might contribute to a sensory interaction despite the dichoptic viewing conditions. Importantly, these cells are selectively tuned for several features, including orientation, color, and shape. Accordingly, we made the cue and the target different shapes and presented them in different colors, in order to reduce sensory interactions in higher visual areas. Finally, rather than presenting the cue and the target at the same location on valid-cue trials, we presented the target $4^{\circ}$ above the cue on valid-cue trials. In Experiment 2 , then, the cue and the target (1) were always presented at different locations, (2) were colored and shaped differently, and (3) were seen in different eyes. Although it is conceivable that some cells in higher visual areas respond to both the cue and the target under these conditions, sensory interactions in general should have been greatly reduced by these procedures. Furthermore, we included a very short SOA that we reasoned would be most likely to be subject to any remaining sensory refractoriness. Our goal in this experiment was to examine the ERP effects associated with IOR under these conditions and to compare them with those observed when sensory refractoriness was more likely (Experiment 1).

\section{Method}

Subjects. Fifteen subjects ( 4 female, 11 male) participated in the experiment. All of the subjects (ages, 19-52 years; mean age, 25 years) were right-handed and had normal or corrected-to-normal vision.

Stimuli and Apparatus. The stimuli and apparatus were the same as those in Experıment 1, except for the following. First, the location markers were changed from unfilled boxes surrounding the target locations to bars positioned $4^{\circ}$ below the target positions. Second, complementary color filters were placed in front of the target and bar marker locations, so that the cues differed in color from the targets. Green filters were placed in front of the location marker/cue positions, and red filters were placed in front of the target positions. During testing, the subjects wore eyeglasses with a green filter in front of the left eye and a red filter in front of the right eye. The transmittance of the eye filters matched that of the display filters, so that the green cue could only be seen by the left eye, whereas the red cue could only be seen by the right eye.

Procedure. The procedures were the same as those in Experiment 1 , except that the SOA intervals were now $100-300$ and 500$700 \mathrm{msec}$.

Electrophysiological recording. Brain potentials and EOG were recorded, using the same procedures as those described in Experiment 1 , except that the signals were amplified with a band-pass of $0.1-100 \mathrm{~Hz}$.

Data analysis. Analyses of the behavioral and ERP data were similar to those in Experiment 1. Preliminary analyses of the ERPs showed that the posterior Nd occurred only at the $100-300 \mathrm{msec}$ SOA, whereas cue validity influenced the amplitude of individual ERP components at the 500-700 msec SOA. Consequently, amplitude measures were taken for latency windows centered on the P1 (130-180 msec), N1 (180-210 msec), P2 (210-300 msec), and P3 $(320-500 \mathrm{msec})$ peaks for the $500-700 \mathrm{msec}$ SOA and for latency windows centered on the posterior $\mathrm{Nd}(120-290 \mathrm{msec})$ and P3 ( $320-500 \mathrm{msec})$ for the $100-300 \mathrm{msec}$ SOA. Again, we computed valid-invalid difference waves to determine the latency window of the posterior $\mathrm{Nd}$. The difference waves revealed a broad, unimodal negativity that began $120 \mathrm{msec}$ after onset of the target and continued for almost $200 \mathrm{msec}$. Accordingly, the mean amplitude of the posterior Nd was computed within the 120-290 msec latency window. A separate P2 was not calculated for the $100-300 \mathrm{msec}$ SOA.

\section{Results}

Behavioral performance. Responses occurred on $3.2 \%$ of the no-target catch trials. Less than $2 \%$ of the trials were removed from the analysis because the RT was less than $100 \mathrm{msec}$ or greater than $1,000 \mathrm{msec}$. Median RTs were calculated from the remaining data for each subject in each of the eight visual field $\times$ validity $\times$ SOA conditions. The means of these median RTs and the corresponding cue effects (invalid RT - valid RT) are shown in Table 1.

There was no main effect of SOA $[F(1,11)=2.1, p=$ $.174]$, visual field $[F(1,11)=0.38, p=.6]$, or validity $[F(1,11)=1.0, p=.3]$ in Experiment 2. However, SOA and validity interacted significantly $[F(1,11)=9.9, p=$ $.009]$, indicating that the nonpredictive spatial cue influenced RTs differently at the two cue-target intervals. As in the previous experiment, the subjects were slower to respond to targets on valid-cue trials than on invalid-cue trials at the 500-700 msec SOA. There was a slight trend for faster responses on valid-cue trials than on invalidcue trials at the 100-300 msec SOA. However, planned comparisons showed that the cue effects were significant only at the longer SOA. This pattern of results is consistent with previous findings indicating that (1) IOR does not fully develop until after about $300 \mathrm{msec}$ (Posner \& Cohen, 1984) and (2) the facilitatory effect at short SOAs is small, particularly when sensory interactions between cue and target are reduced (Tassinari, Aglioti, Chelazzi, Peru, \& Berlucchi, 1994).

Event-related potentials. Figures 4 and 5 display the grand-averaged ERP waveforms elicited by the target when the SOA varied randomly between $100-300 \mathrm{msec}$ and 500-700 msec, respectively. The prominent ERP deflections observed at the 500-700 msec SOA resembled those found in Experiment 1. These included an occipital P1 (130-180 msec), an occipito-parietal N1 (180$210 \mathrm{msec})$, and a parieto-central P3 (320-500 msec). The $\mathrm{N} 1$ peak was again largest over contralateral sites, whereas the $\mathrm{P} 1$ and $\mathrm{P} 3$ peaks were more symmetrically distributed. A symmetrically distributed P2 $(210-300 \mathrm{msec})$ can also be seen at ipsilateral occipital sites. The prestimulus baseline was relatively flat at each electrode site, indicating that there was very little distortion produced by the overlapping ERP to the cue. By comparison, the ERP waveforms observed at the 100-300 msec SOA were distorted by the overlapping ERP to the cue (see Figure 4). Despite this distortion, $\mathrm{P} 1, \mathrm{~N} 1$, and $\mathrm{P} 3$ peaks could still be seen in the waveforms. We made no attempt to remove the overlapping response to the cue, because our primary goals were to examine the effects of cue validity at the 500-700 msec cue-target SOA and to compare these with those found in Experiment 1.

For the 100-300 msec SOA, the earliest effect of cue validity was a modulation of the posterior $\mathrm{Nd}$ in the 120 $290 \mathrm{msec}$ latency window. This effect was significant at 
IPSILATERAL
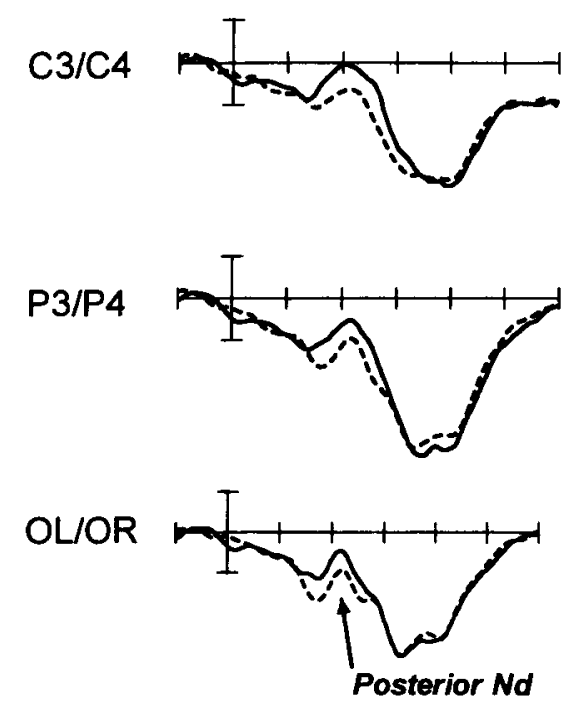

\section{CONTRALATERAL}
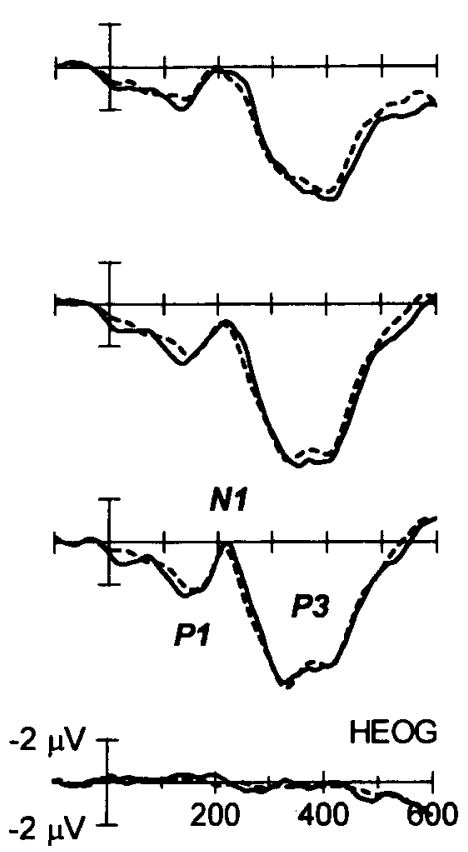

Figure 4. Grand-averaged event-related potentials in response to targets preceded $100-300$ msec by a valid (solid line) or invalid (dashed line) cue in Experiment 2. Waveforms are averaged across left-field and right-field target stimuli. Electrode positions are labeled as in Figure 2.

central $[F(1,14)=7.8, p=.01]$ and parietal $[F(1,14)=4.9$, $p=.05]$ sites. At occipital sites, an interaction occurred between cue validity, visual field, and recording hemisphere $[F(1,6)=8.2, p=.01]$. Figure 4 shows that this interaction occurred because the posterior Nd effect occurred at ipsilateral sites, but not at contralateral sites. The posterior Nd was also larger ipsilaterally at central $[F(1,14)=14.8, p=.002]$ and parietal $[F(1,14)=10.1$, $p=.007]$ sites. Cue validity did not influence the amplitude of P3 for the $100-300 \mathrm{msec}$ SOA.

For the 500-700 msec SOA, the earliest effect of cue validity on the ERP waveforms was a modulation of the Pl peak. This effect was significant at ipsilateral occipital sites $[F(1,14)=4.7, p=.05]$. Inspection of Figure 5 reveals that the $P 1$ was smaller on valid-cue trials than on invalid-cue trials. A similar effect of cue validity was observed in the P2 latency window: The P2 was smaller on valid-cue trials than on invalid-cue trials. This effect was significant at central $[F(1,14)=4.4, p=.009]$, parietal $[F(1,14)=9.7, p=.008]$, and occipital $[F(1,14)=9.3, p=$ $.009]$ electrode sites. Cue validity did not influence the amplitude of the $\mathrm{N} 1$ or $\mathrm{P} 3$ peaks for the $500-700 \mathrm{msec}$ SOA.

Electrooculograms. As in Experiment 1, we examined the grand-averaged EOG recordings during the cuetarget interval, to determine whether there were any con- sistent trends for the subjects to look in the direction of the cue. The EOG recordings did not exceed $\pm 1.5 \mu \mathrm{V}$, indicating that the subject's eye position was within $0.10^{\circ}$ of the central LED during the entire cue-target interval in Experiment 2.

\section{Discussion}

The results of Experiment 2 replicated the behavioral and ERP findings of Experiment 1 under conditions in which sensory interactions were reduced. Because the cue and the target were seen in different eyes, our findings support previous conclusions that local changes in retinal sensitivity at the cued location are not responsible for the behavioral IOR effect (Maylor, 1983; Tassinari \& Berlucchi, 1993). More important, our findings extend these conclusions by demonstrating that reduction of $P 1$ (and P2) on valid-cue trials persists under dichoptic viewing conditions. Local changes in retinal sensitivity, therefore, do not cause the behavioral IOR effect or P1 (and P2) reduction on valid-cue trials.

Sensory interactions at higher levels of the visual system were also reduced in the present experiment because the cue and the target were seen in different eyes, were separated by $4^{\circ}$ on valid-cue trials, and were colored and shaped differently. Despite this general reduction in sensory interaction, the P1 was smaller on valid-cue trials 

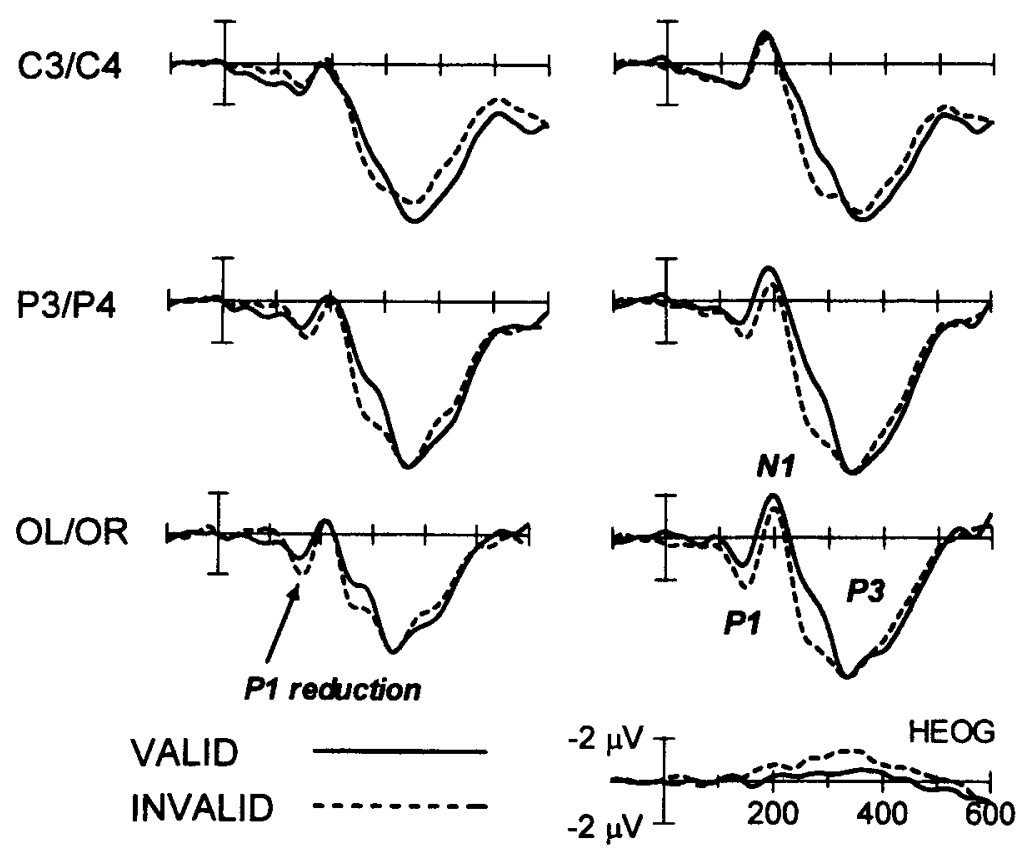

\begin{abstract}
Figure 5. Grand-averaged event-related potentials in response to targets preceded 500-700 msec by a valid (solid line) or invalid (dashed line) cues in Experiment 2. Waveforms are averaged across left-field and right-field target stimuli. Electrode positions are labeled as in Figure 2.
\end{abstract}

than on invalid cue trials over ipsilateral occipital sites. Notably, in this experiment, the $\mathrm{P} 1$ reduction occurred at the 500-700 msec SOA. By comparison, cue validity influenced the amplitude of the ERP waveforms over a much longer latency window at the 500-700 msec SOA in Experiment 1 - that is, it produced the posterior $\mathrm{Nd}$. Thus, we observed qualitatively different ERP effects at different SOAs (Experiment 1) and at the same SOA when measures were taken to reduce sensory interaction (Experiment 1 vs. Experiment 2): P1 reduction occurred when sensory interactions were likely to be smaller (longer SOA in both experiments), whereas the posterior Nd occurred when sensory interactions were likely to be larger (shorter SOA in both experiments). These findings support our previous conclusions that the $\mathrm{P} 1$ reduction is related to IOR, whereas the posterior Nd is possibly related to sensory refractoriness.

Interestingly, there was no ERP evidence for stimulusdriven attentional enhancement at the $100-300 \mathrm{msec}$ SOA. Although there was a small trend for faster responses on valid-cue trials than on invalid-cue trials, this effect did not reach statistical significance. It is possible that the 100-300 msec SOA interval contained a mixture of trials on which a facilitatory effect occurred (SOAs $<200 \mathrm{msec}$ ) and on which IOR occurred (SOA $>200 \mathrm{msec}$ ). However, a posterior $\mathrm{Nd}$ occurred over ipsilateral sites at the
100-300 msec SOA, indicating that a facilitatory effect of attention could have been masked by a counteracting effect of sensory refractoriness. Despite our efforts to minimize sensory interaction in Experiment 2, some neurons in higher visual cortical areas could have responded to both the cue and the target when the SOA was between 100 and $300 \mathrm{msec}$. The occurrence of the posterior $\mathrm{Nd}$ in the absence of an inhibitory $\mathrm{RT}$ effect provides additional evidence that it is not related to IOR.

The $P 2$ peak was also smaller on valid-cue trials than on invalid-cue trials at the 500-700 msec SOA. This effect was larger than the negative difference occurring at the 100-300 msec SOA and was distributed more symmetrically across the scalp. Like the $\mathrm{P} 1$ reduction, then, it is likely that the $\mathrm{P} 2$ reduction reflects IOR, rather than sensory refractoriness. However, it is likely that the P1 and $\mathrm{P} 2$ reductions reflect different inhibitory effects, since the P2 effect occurred 100 msec later than the P1 effect and was distributed slightly more anteriorly.

\section{GENERAL DISCUSSION}

The recording of ERPs has been a useful tool for studying covert spatial orienting in humans. Most previous ERP studies of covert spatial orienting have used sustained attention or symbolic-cuing paradigms to examine the ef- 
fects of voluntary attention on brain potentials. However, a few recent ERP studies have examined the effects of covert orienting when the location of a target was cued directly by a stimulus appearing at a potential target location. These studies focused primarily on the facilitatory effects of covert orienting under direct-cuing conditions (Anllo-Vento, 1995; Eimer, 1994; Hopfinger \& Mangun, 1998). By comparison, the present study examined the inhibitory effects of nonpredictive direct spatial cues. Specifically, we used ERPs in conjunction with behavioral measures to determine the electrophysiological consequences of IOR. Subjects in two different experiments responded more slowly to targets that appeared at or near the cued location, relative to targets that appeared on the opposite side of fixation, when the cuetarget SOA was longer than $500 \mathrm{msec}$. Thus, our behavioral results replicated several previous findings of IOR in vision (e.g., Maylor, 1985; Maylor \& Hockey, 1985; Posner \& Cohen, 1984; Posner et al., 1985; Rafal et al., 1989; Tassinari et al., 1987). In the experiments reported here, IOR was associated with cue-validity effects on several components of the target-elicited ERP waveforms. The earliest such effect was a smaller occipital P1 on valid-cue trials, which we interpret here as a $\mathrm{P} 1$ reduction. The later P2 component was also smaller on valid-cue trials, indicating that nonpredictive spatial cues influence multiple stages of information processing at relatively long cue-target intervals.

One consideration that affects all direct-cuing studies is that sensory interactions between cue and target are likely to be different on valid-cue trials than they are on invalid-cue trials and, thus, the behavioral and ERP effects of direct cues might reflect sensory processes, as well as attentional or oculomotor processes. Depending on many situational parameters, sensory processes might enhance or suppress perceptual processing of stimuli appearing at the cued location, whether or not attention is engaged there. On the one hand, neurons that responded to a cue still might be responding above their background rate when the target appears, resulting in more vigorous responding to the target (sensory summation). On the other hand, such neurons might be responding below their background rate when the target appears, resulting in less vigorous responding to the target (sensory refractoriness). In light of these potential sensory effects, additional information is required in order to interpret directcuing effects in terms of attentional or oculomotor processes.

In order to help interpret the ERP effects associated with behavioral IOR, we manipulated the strength of cue-target sensory interactions in two different ways. First, we systematically varied the cue-target SOA within each experiment. Although sensory summation might occur under some conditions when the SOA is very short (see Tassinari et al., 1994), sensory refractoriness also should be greatest at very short SOAs, whereas IOR should be greatest at longer SOAs. Second, we reduced the strength of sensory interactions in Experiment 2 by presenting the cue and the target in different eyes, at different locations, and in different colors and shapes. As was expected, qualitatively different ERP effects were observed for the different cue-target SOAs in Experiment 1 . For the 500-700 msec SOA, cue validity influenced the amplitude of the early ERP components over a relatively long latency window. This sustained effect, which we called the posterior $\mathrm{Nd}$, could reflect a reduced positivity on valid-cue trials, relative to invalid-cue trials, because it occurred when sensory refractoriness was more likely. For the 900-1,100 msec SOA, cue validity influenced the amplitude of the occipital Pl, and, unlike the posterior $\mathrm{Nd}$, this effect was not sustained. On the basis of these results, we suggested that the posterior $\mathrm{Nd}$ was possibly caused by sensory refractoriness, whereas the PI reduction was associated with IOR. The results of Experiment 2 were consistent with this suggestion. A posterior Nd occurred for the 100-300 msec SOA, as it did at the shorter SOA in Experiment 1, perhaps because the dichoptic viewing conditions of Experiment 2 did not entirely eliminate sensory refractoriness at that SOA. By comparison, a separate effect of cue validity on the $\mathrm{Pl}$ component was found at the 500-700 msec SOA in Experiment 2, similar to that observed at the 900$1,100 \mathrm{msec}$ SOA in Experiment 1 (see Figures 3 and 4). Critically, experimental conditions were such that sensory interactions between the cue and the target were likely to be minimal in both cases.

The present investigation thus provides the first demonstration of ERP differences that are both associated with behavioral IOR and not likely to be caused by sensory refractoriness. The earliest effect, a smaller Pl on validcue trials, was the opposite of the usual effect observed in symbolic-cuing tasks, in which validly cued targets typically elicit a larger P1 component at long SOAs (see, e.g., Mangun \& Hillyard, 1991). The latter Pl effect is thought to reflect attentional modulation of early perceptual processes, since similar effects are found in sustained attention paradigms (e.g., Eason, 1981; Harter et al., 1982; Hillyard \& Mangun, 1987; Mangun \& Hillyard, 1988; Rugg et al., 1987). The scalp distribution and peak latency of this Pl enhancement strongly suggest that it is generated in the extrastriate visual cortex along the ventral stream of visual cortical processing (Mangun \& Hillyard, 1990; Mangun et al., 1993). Given the relatively sparse electrode array used in the present experiments, we have not provided a detailed topographic analysis of $\mathrm{P} 1$ reduction. However, the $\mathrm{P} 1$ reduction was found to be largest over lateral occipital recording sites, primarily in the ipsilateral hemisphere, indicating that it may also reflect changes in neural activity within extrastriate visual cortical areas. Further ERP experiments using dense electrode arrays are required to determine more precisely the source of $\mathrm{P} 1$ reduction in simple detection tasks.

The reduction of the PI component obtained in the present investigation supports the proposal that IOR at least partly reflects suppression of sensory-perceptual processing. Our results are consistent with several pos- 
sible mechanisms as the source of this suppression. These mechanisms include modulation of attention to stimuli at the cued location (e.g., Reuter-Lorenz et al., 1996), oculomotor preparation (Rafal et al., 1989), and oculomotor suppression (Tassinari et al., 1987). We speculate that the posterior $\mathrm{Nd}$ reflects a sensory component of IOR, whereas the P1 reduction reflects an attentional component of IOR (see Tassinari \& Berlucchi, 1993). Importantly, the $P 1$ reduction disconfirms the proposal that IOR uniquely reflects suppression of response processes. The P3 enhancement that was observed in Experiment 1 provides some indication that IOR also might arise, in part, from changes at decisional or response-related stages of information processing. However, no P3 effect was observed in Experiment 2, suggesting that IOR can occur in the absence of the decisional or response-related effects that modulate $\mathrm{P} 3$.

The reduction of the $\mathrm{P} 2$ component reflects cue-validity effects at relatively late stages of information processing. Since there was a relatively small difference between the time of occurrence of the P2 (peak latency was about $270 \mathrm{msec}$ ) and that of the subjects' response (mean RT was 305-355 msec), the P2 effect could be related to changes in decisional or response processing. However, selective attention is known to affect several components of the ERP, including late ones. Thus, reduction of the P2 could also arise from an inhibition of attentional processes at the cued location, rather than from a separate inhibition of responding. Again, future research using dense electrode arrays is needed to determined whether the P2 effect is generated within motor areas of the scalp or within sensory areas, such as the occipital and parietal cortices.

\section{REFERENCES}

ANLLo-VENTO, L. (1995). Shifting attention in visual space: The effects of peripheral cuing on brain cortical potentials. International Journal of Neuroscience, 80, 353-370.

Cheal, M., Chastain, G., \& Lyon, D. R. (1998). Inhibition of return in identification tasks. Visual Cognition, 5, 365-388.

Cl.ARK, V. P., \& HillyaRd, S. A. (1996). Spatial selective attention affects early extrastriate but not striate components of the visual evoked potential. Journal of Cognitive Neuroscience, 8, 387-402.

Donchin, E. (1981). Surprise! . . Surprise? Psychophysiology, 18, 493-513.

EASON, R. G. (1981). Visual evoked potential correlates of early neural filtering during selective attention. Bulletin of the Psychonomic Society, 18, 203-206.

EIMER, M. (1994). An ERP study on visual spatial priming with peripheral onsets. Psychophysiology, 31, 154-163.

Gibson, B. S., \& EGETH, H. (1994). Inhibition and disinhibition of return: Fvidence from temporal order judgments. Perception \& Psychophysics, 56, 669-680.

Harter, M. R., Aine, C., \& Schroeder, C. (1982). Hemispheric differences in the neural processing of stımulus location and type: Effects of selective attention on visual evoked potentials. Neuropsychologia, 20, 421-438.

Heinze, H. J., Mangun, G. R., Burchert, W., Hinrichs, H., Scholz, M., Münte, T. F., Gös, A., Scherg, M., Johannes, S., Hundershagen, H., Gazzaniga, M. S., \& Hillyard, S. A. (1994). Combined spatial and temporal imaging of brain activity during visual selective attention in humans. Nature, 372, 543-546.

Hillyard, S. A., LuCk, S. J., \& Mangun, G. R. (1994). The cuing of attention to visual field locations: Analysis with ERP recordings. In H. J. Heinze, T. F. Münte, \& G R. Mangun (Eds.), Cognitive electrophysiology: Event-related brain potentials in basic and clinical research (pp. 1-25). Boston: Birkhäuser.

Hillyard, S. A., \& Mangun, G. R. (1987). Sensory gating as a physiological mechanism for visual selective attention. In R. Johnson, R. Parasuraman, \& J. W Rohrbaugh (Eds.), Current trends in eventrelated potential research (pp. 61-67). Amsterdam. Elsevier.

Hopfinger, J. B., \& MANGUN, G. R. (1998). Reflexive attention modulates processing of visual stımuli in human extrastriate cortex. Psychological Science, 9, 441-447.

JONIDES, J. (1981). Voluntary versus automatic control over the mind's eye's movement. In J. [B.] Long \& A. [D.] Baddeley (Eds.), Attention and performance $I X$ (pp. 187-203). Hillsdale, $\mathrm{NJ}$ - Erlbaum.

Jonides, J., \& MACK, R. (1984). On the cost and benefit of cost and benefit. Psychological Bulletin, 96, 29-44

Klein, R. M., SChmidT, W. C., \& Müller, H. J. (1998). Dısınhibitıon of return: Unnecessary and unlikely. Perception \& Psychophysics, 60, 862-872.

KLEIN, R. M., \& TAYLOR, T L. (1994). Categories of cognitive inhibition with reference to attention. In D. Dagenbach \& T. H. Carr (Eds.), Inhibitory processes in attention, memory, and language (pp. 113150). San Diego: Academic Press

LABERGE, D. (1995). Attentional processing The brain's art of mindfulness. Cambridge, MA: Harvard University Press.

MANGUN, G. R (1995). Neural mechanisms of visual selective attention. Psychophysiology, 32, 4-18.

Mangun, G. R., \& HiLlyaRd, S. A. (1988). Spatial gradients of visual attention: Behavioral and electrophysiological evidence. Electroencephalography \& Clinical Neurophysiology, 70, 417-428.

Mangun, G. R., \& Hillyard, S. A. (1990). Electrophysiological studies of visual selective attention in humans. In A. B. Scheibel \& A. F Wechsler (Eds.), Neurobiology of higher cognitive function (pp. 271295). New York: Guilford.

MANGUN, G. R., \& HillyaRd, S. A. (1991). Modulations of sensoryevoked brain potentials indicate changes in perceptual processing during visual-spatial priming. Journal of Experimental Psychology Human Perception \& Performance, 17, $1057-1074$.

Mangun, G. R., Hillyard, S. A., \& LuCK, S. J. (1993). Electrocort1cal substrates of visual selective attention. In D. E. Meyer \& S. Kornblum (Eds.), Attention and performance XIV Synergies in experimental psychology, artificial intelligence, and cognitive neuroscience (pp. 219-243). Cambridge, MA: MIT Press.

MAYLOR, E. A. (1983). Components of orienting in visual space. Unpublished doctoral thesis, University of Durham.

MAYLOR, E. A. (1985). Facilitatory and inhibitory components of orienting in visual space. In M I. Posner \& O. S. M. Marın (Eds.), Attention and performance $X I$ (pp. 189-207). Hillsdale, NJ: Erlbaum.

MAYLOR, E. A., \& HOCKEY, R. (1985). Inhibitory component of externally controlled orienting in visual space. Journal of Experimental Psychology: Human Perception \& Performance, 11, 777-787.

PoSNER, M. I., \& COHEN, Y. (1984). Components of visual orienting. In H. Bouma \& D. G. Bouwhus (Eds.), Attention and performance $X$ Control of language processes (pp. 531-556). Hillsdale, NJ Erlbaum Posner, M. I., Rafal, R. D., Choate, L. S., \& Vaughan, J. (1985). Inhibition of return: Neural basis and function. Cognitive Neuropsychology, 2, 211-228.

PratT, J. (1995). Inhibition of return in a discrimination task. Psychonomic Bulletin \& Review, 2, 117-120.

Pratt, J., Kingstone, A., \& Khoe, W. (1997). Inhibition of return in location and identity based choice decision tasks. Perception \& Psychophysics, 59, 964-971.

Rafal, R. D., Calabresi, P., Brennan, C. W., \& Sciolto, T. K. (1989) Saccade preparation inhibits reorienting to recently attended locations. Journal of Experimental Psychology: Human Perception \& Performance, 15, 673-685.

RaFal, R. D., \& HENIK, A. (1994). The neurology of inhibition: Integrating controlled and automatic processes. In T H. Carr \& D. Dagenbach (Eds.), Inhibitory processes in attention, memory, and language (pp. 1-51). San Diego: Academic Press. 
Reuter-Lorenz, P. A., Jha, A. P., \& Rosenquist, J. N. (1996). What is inhibited in inhibition of return? Journal of Experimental Psychology: Human Perception \& Performance, 22, 367-378.

Rugg, M. D., Milner, A. D., Lines, C. R., \& Phalp, R. (1987). Modulation of visual event-related potentials by spatial and non-spatial visual selective attention. Neuropsychologia, 25, 85-96.

Stelmach, L. B., \& Herdman, C. M. (1991). Directed attention and the perception of temporal order. Journal of Experimental Psychology. Human Perception \& Performance, 17, 539-550.

SteRnberG, S., \& KNOL.L, R. L. (1973). The perception of temporal order: Fundamental issues and a general model. In S. Kornblum (Ed.), Attention and performance IV (pp. 629-685). New York: Academic Press.

Tassinari, G., Aglioti, S., Chelazzi, L., Marzi, C. A., \& Berlucchi, G. (1987). Distribution in the visual field of the costs of voluntarily allocated attention and of the inhibitory after-effects of covert orienting. Neuropsychologia, 25, 55-72.

Tassinari, G., Aglioti, S., Chelazzi, L., Peru, A., \& Berlucchi, G. (1994). Do peripheral non-informative cues induce early facilitation of target detection? Vision Research, 34, 179-189.

TASSinari, G., \& Berlucchi, G. (1993). Sensory and attentional components of slowing of manual reaction-tıme to non-fixated visual targets by ipsilateral primes. Vision Research, 33, 1525-1534.

TERRY, K. M., VALDES, L. A., \& NeILl, W. T. (1994). Does "inhibition of return" occur in discrimination tasks? Perception \& Psychophysics, 55, 279-286.

TipPer, S P., Driver, J., \& Weaver, B. (1991). Object-centered ınhı- bition of return of visual attention. Quarterly Journal of Experimental Psychology, 43A, 289-298.

UNGERLEIDER, L. G., \& MishKIN, M. (1982). Two cortical visual systems. In D. J. Ingle, M. A. Goodale, \& R. J. W. Mansfield (Eds.), Analysis of visual behavior (pp. 549-586). Cambridge, MA: MIT Press.

VAN DER HeIJDen, A. H. C. (1992). Selective attention in vision. New York: Routledge.

WRIGHT, R. D., \& RichaRD, C. M. (1996). Inhibition-of-return at multiple locations in visual space. Canadian Journal of Experimental Psychology, 54, 324-327.

Wright, R. D., RichaRd, C. M., \& MCDonald, J. J. (1995). Neutral location cues and cost/benefit analysis of visual attention shifts. Canadian . Iournal of Experimental Psychology, 49, 540-548.

WRIGHT, R. D., \& WARD, L. M. (1998). The control of visual attention. In R. D. Wright (Ed.), Visual attention (pp. 132-186). New York: Oxford University Press.

\section{NOTE}

1. Bonferroni $t$ tests were performed, using the $M S_{\mathrm{e}}$ from the visual field $\times$ cue validity $\times$ SOA interaction to calculate the critical difference for the cue-validity effects. All such tests were done two-tailed, with $\alpha=.025$ on each contrast (i.e., FW $=4 \times 0.025=0.10$ ).

(Manuscript received December 10, 1996; revision accepted for publication July 27,1998 .) 